Research Article

\title{
Predicting the Healthy Operation of Heavy Oil Well Casings in Permafrost Regions
}

\author{
Tiecheng Sun $\mathbb{D}^{1},{ }^{1,2,3}$ Cancan Liu, ${ }^{3}$ Zurun Yue, ${ }^{1,2,3}$ Tianfei Hu, ${ }^{1,2,3}$ and Yiming Liao ${ }^{3}$ \\ ${ }^{1}$ State Key Laboratory of Mechanical Behavior and System Safety of Traffic Engineering Structures, \\ Shijiazhuang Tiedao University, Shijiazhuang 050043, China \\ ${ }^{2}$ Key Laboratory of Roads and Railway Engineering Safety Control (Shijiazhuang Tiedao University), Ministry of Education, \\ Shijiazhuang 050043, China \\ ${ }^{3}$ School of Civil Engineering, Shijiazhuang Tiedao University, Shijiazhuang 050043, China \\ Correspondence should be addressed to Tiecheng Sun; sjz_sti@stdu.edu.cn
}

Received 18 September 2020; Revised 6 November 2020; Accepted 30 November 2020; Published 26 March 2021

Academic Editor: Yu-Sheng Shen

Copyright $(2021$ Tiecheng Sun et al. This is an open access article distributed under the Creative Commons Attribution License, which permits unrestricted use, distribution, and reproduction in any medium, provided the original work is properly cited.

This study explores the distribution of stress and deformation on casings in heavy oil recovery wells and the distribution of stress in the thaw bulb in permafrost areas. Considering the expansion of the thaw bulb, the simulation analysis method is used to explore the internal mechanisms of vertical settlement displacement development and stress redistribution within thawed soil and casing. Calculation results show the following: (a) The maximum settlement of the thawed soil and the casing was positively correlated with the expansion of the thaw bulb. Although the settlement of the thawed soil was greater than that of the casing, the initial increase in maximum settlement difference between the thawed soil and the casing eventually tended to be constant due to stabilization of the thaw bulb's expansion. (b) The size of the thaw bulb directly affects the redistribution of internal stress in thawed soil, leading to different distribution rules for the vertical displacement of thawed soil and casing with depth. (c) Beyond a certain formation depth, the vertical stress of thawed soil gradually transits from a tensile stress state to a compressive stress state. The depth of a soil layer whose horizontal stress value is initially greater than its vertical stress value will gradually deepen with an increase in thaw bulb radius. (d) There is no significant negative friction on the lateral wall of casing in yield state, but significant negative friction exists on the lateral wall of casing in elastic state. The vertical stress of casing in elastic state increased gradually with the increase of casing depth, due to the existence of continuous negative friction and dead weight.

\section{Introduction}

With the gradual increase of the global temperature, largescale development of Arctic oil and gas resources has become possible. In the late 1960s, a large number of oil wells began to appear in the Arctic region. Many of them are still in operation. In the process of heavy oil production, large bending and shear deformation of oil well casings made it difficult to operate the oil wells. Excessive strain leads to breakage at casing joints, which eventually leads to failure of the oil well [1-5]. Casing damage and tubing deformation [6] are shown in Figure 1. Scientists have carried out fruitful research on how to reduce casing deformation by examining the causes of casing stress [7-10], casing design methodology [11-16], oil well construction techniques, and the technology of heavy oil recovery [17-21]. However, in terms of factors affecting casing stress, there has been little research on the interactions between soil layer and oil well casing.

Oil well casing in polar permafrost areas employs a thaw bulb with positive temperature between the casing and the permafrost. The size of the thaw bulb will change with the extension of oil well operation time. The continuous expansion of the thaw bulb complicates stress and deformation exerted on the casing. In order to deeply understand the interactions between the thawed soil and the casing in the thaw bulb and to further explore the internal mechanisms of casing settlement deformation, this paper uses the simulation analysis method to analyze and predict the stress and deformation of a single oil well casing. Stress distribution 


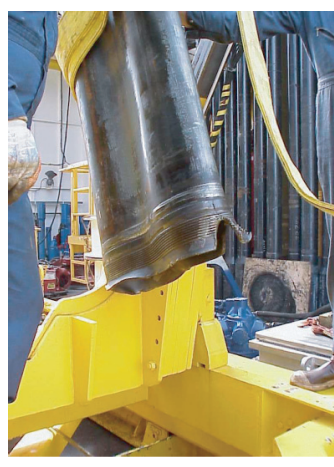

(a)

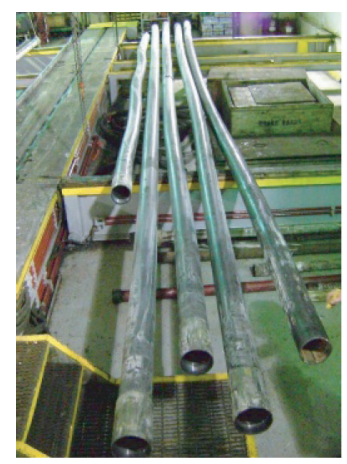

(b)

FIgURE 1: Deformation of the oil well components: (a) the casing and (b) the tubing.

laws within the thaw bulb are analyzed on the basis of changes occurring within the thaw bulb. As such, this research may provide a theoretical reference for the design of new oil wells and important technical support for settlement control measures for existing oil wells. At the same time, it will provide technical suggestions for China's participation in oil and gas development in polar permafrost regions. Although China is an extraterritorial country in the Arctic region, the country can participate in the development and utilization of resources in the region according to "The Svalbard Treaty."

\section{Model}

2.1. Assumptions. To simplify analysis, the following assumptions were made:

(1) In the analysis of casing stress and deformation, additional stress caused by casing connection errors was considered negligible. That is, to allow for simple analysis of the friction between the soil layer and the casing, the casing was assumed to be a linear pipe body.

(2) The thermal properties of thawed soil layer, permafrost soil layer, and casing were not considered. It has been assumed that there was no heat transfer inside the thaw bulb, in the permafrost region, between the thawed soil and the casing or between the thaw bulb and the permafrost. The model boundary was assumed to be adiabatic.

(3) The model did not take the moisture field of the soil layer into account; that is, it assumed that no water migration occurred in the soil layer.

2.2. Geometric Parameters. According to the measurements of an existing oil well [22], a casing with an inner diameter of $22.3 \mathrm{~cm}$, an outer diameter of $24.5 \mathrm{~cm}$, and a wall thickness of $1.1 \mathrm{~cm}$ was used. On the basis of data from a field investigation report [6], the soil layer in the model was divided into 14 layers to reflect conditions on the ground. The type and thickness of each soil layer are shown in Table 1 and 2. Matthews et al. [6] carried out an ice-melting assessment for a single well model with an average radius $R_{\mathrm{TB}}$ for the thaw bulb represented by the change of thaw bulb over time. The thaw bulb radius $R_{\mathrm{TB}}$ was $1.0 \mathrm{~m}, 3.0 \mathrm{~m}, 5.0 \mathrm{~m}$, and $7.5 \mathrm{~m}$, which corresponded to the thaw bulb radius over the course of the oil well operation period at 1 year, 5 years, 10 years, and more than 20 years, respectively. According to these data, a cylindrical model with a radius of $22.5 \mathrm{~m}$ and a vertical depth of $171 \mathrm{~m}$ was determined for calculation and analysis. The model grid number was 166460 . The casing was modeled using the 8-node quadrilateral in-plane generalpurpose continuum shell element (SC8R). The soil was modeled using 8-node linear brick elements (C3D8R) or 6node linear triangular prism elements (C3D6). The specifics of the model are illustrated in Figure 2.

2.3. Physical and Mechanical Parameters. In actual oil well engineering, casing adopts J55 steel pipe. For the model, the pipe's physical and mechanical properties were obtained by referring to relevant literature [23]. Specific parameters are listed in Table 3.

The physical and mechanical parameters for each soil layer were determined partly on the basis of existing literature [24]. The remaining parameters [25] were obtained through indoor tests. The physical and mechanical parameters of the soil layers are shown in Tables 2 and 3.

Contact surfaces were set up between the casing and the thawed soil and the thawed soil and the permafrost. Contact parameters were measured through laboratory testing and are listed in Table 4.

2.4. Model Constitutive and Others. Through experimentation, it was found that thawed soil formed by the thawing of permafrost demonstrated strong nonlinearity. For this reason, the Mohr-Coulomb model was selected to calculate nonlinearity in the numerical simulation. According to the literature [26], the relationship between Young's modulus for soil and the confining pressure is shown in

$$
E=E_{0}\left(\frac{P}{P_{\alpha}}\right)^{\alpha}
$$

where $E_{0}$ is Young's modulus at a reference pressure, $P$ is the mean confining pressure, $P_{\alpha}$ is the reference pressure (usually a standard atmospheric pressure), and $\alpha$ is the 
TABLE 1: Soil layer division and physical and mechanical parameters.

\begin{tabular}{|c|c|c|c|c|c|c|c|c|c|}
\hline \multirow[t]{2}{*}{ Layer } & \multirow[t]{2}{*}{ Soil type } & \multirow[t]{2}{*}{ Depth (m) } & \multirow[t]{2}{*}{ Density $\left(\mathrm{kg} / \mathrm{m}^{3}\right)$} & \multicolumn{2}{|c|}{$\begin{array}{c}\text { Internal } \\
\text { friction angle } \\
\left({ }^{\circ}\right)\end{array}$} & \multicolumn{2}{|c|}{$\begin{array}{l}\text { Dilatancy } \\
\text { angle }\left(^{\circ}\right)\end{array}$} & \multicolumn{2}{|c|}{$\begin{array}{l}\text { Cohesive force } \\
\qquad(\mathrm{kPa})\end{array}$} \\
\hline & & & & $F^{*}$ & $T^{+}$ & $F$ & $T$ & $F$ & $T$ \\
\hline 1 & Gravel and sand & $0 \sim 30$ & 1900 & 30 & 32 & 10 & 5 & 1000 & 5 \\
\hline 2 & Silt & $30 \sim 54$ & 1800 & 15 & 20 & 5 & 5 & 2000 & 40 \\
\hline 3 & Silty sand & $54 \sim 63$ & 1900 & 15 & 22 & 5 & 5 & 2000 & 35 \\
\hline 4 & Clay & $63 \sim 69$ & 1750 & 5 & 10 & 0.1 & 0.1 & 2000 & 100 \\
\hline 5 & Sand & $69 \sim 81$ & 1900 & 25 & 30 & 10 & 5 & 1000 & 35 \\
\hline 6 & Clayey silt & $81 \sim 90$ & 1850 & 10 & 17 & 5 & 5 & 2000 & 50 \\
\hline 7 & Silty clay & $90 \sim 96$ & 1900 & 5 & 12 & 0.1 & 0.1 & 2000 & 75 \\
\hline 8 & Silt & $96 \sim 102$ & 1800 & 15 & 20 & 5 & 5 & 2000 & 40 \\
\hline 9 & Sand & $102 \sim 135$ & 1950 & 25 & 30 & 10 & 5 & 1000 & 35 \\
\hline 10 & Silt & $135 \sim 147$ & 1800 & 15 & 20 & 5 & 5 & 2000 & 40 \\
\hline 11 & Sand & $147 \sim 153$ & 1950 & 25 & 30 & 10 & 5 & 1000 & 30 \\
\hline 12 & Clay & $153 \sim 156$ & 1750 & 5 & 10 & 0.1 & 0.1 & 2000 & 100 \\
\hline 13 & Silty sand & $156 \sim 162$ & 1900 & 15 & 22.5 & 10 & 5 & 1000 & 35 \\
\hline 14 & Clay & $162 \sim 171$ & 1750 & 5 & 10 & 0.1 & 0.1 & 2000 & 100 \\
\hline
\end{tabular}

$F^{*}$ indicates permafrost and $T^{+}$indicates thawed soil.

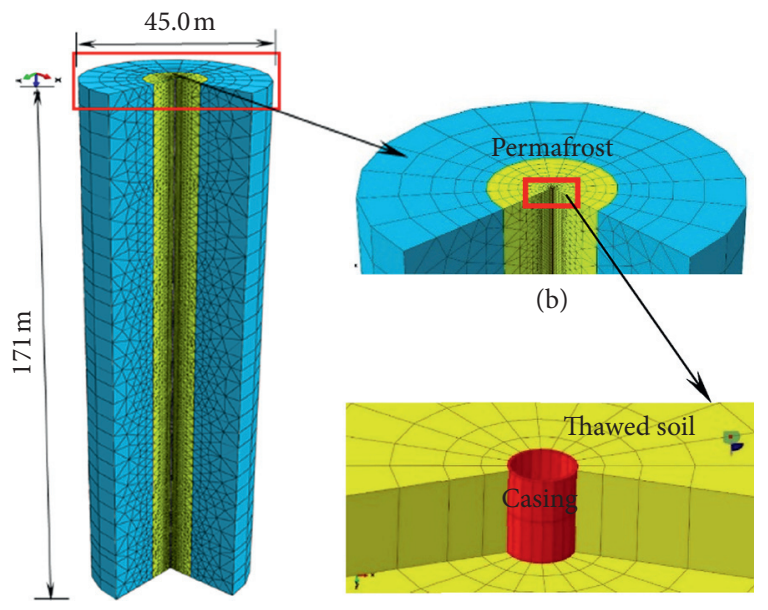

(a)

(c)

FIGURE 2: Size and detailed structure of the model: (a) mesh of the whole model, (b) local mesh of the model, and (c) local mesh of the casing.

confining pressure index. The confining pressure index can generally be taken as 0.5 .

The change in casing stress state occurring during the thawing of frozen soil is closely related to the friction force generated by thawed soil on its contact surface. The friction properties of the contact surface between the casing and the thawed soil were taken to be a key parameter for calculation and analysis. This parameter was necessary to more accurately obtain value of the friction force and to better understand its distribution laws as they apply to the outer contact surface of the casing. In the analysis, the linear attenuation traction-separation model [27] was used to analyze contact behavior.

The model boundary was an adiabatic boundary and a normally fixed constraint was adopted on each surface. In calculation and analysis, the influence of confining pressure on Young's modulus of soil was realized by using a subroutine. The gravity field and the initial tensile stress of the casing were added to the calculation model, and the model was also adjusted to account for the stress balance which occurs to eliminate the initial displacement and deformation caused by the gravity field. The shrinkage/expansion coefficient (determined by strain caused by the thawing of the visible ice lens of the total ice lens in each soil layer and the strain caused by the soil thawing and consolidation in the consolidation test [28]) was used to account for changes to the volume of the soil layer within the thaw bulb. Taking into account the semi-infinite nature of soil in the horizontal direction, its horizontal shrinkage becomes very small due to strong constraints. Therefore, the horizontal shrinkage was ignored in the present analysis. Only the vertical shrinkage of the soil layer was considered.

\section{Analysis of Calculation Results}

3.1. Maximum Settlement and Deformation. The maximum settlement deformation $\mathrm{SC}_{\max }$ and $\mathrm{ST}_{\max }$ of the ground surface and the casing appeared at the top of the casing and the thawed ground surface adjacent to the casing, respectively. The change curve with respect to the thaw bulb radius $R_{\mathrm{TB}}$ is shown in Figure 3 .

As illustrated by the graphs in Figure 3, the maximum settlement of the thawed soil and the casing increases slowly alongside the gradual expansion of the thaw bulb. Moreover, the settlement of thawed soil is greater than that of the casing. The settlement difference between the thawed soil and the casing increases initially before decreasing during the process of the gradual expansion of the thaw bulb. Eventually, thaw bulb expansion within the actual oil well project tends to stabilize, and the settlement difference between the thawed soil and the casing tends towards a constant state.

In the preliminary stage of permafrost thawing, ice lens thawing and thawed soil consolidation cause initial settlement deformation within the thawed soil. The magnitude of 
TABLE 2: Soil layer division and other physical and mechanical parameters.

\begin{tabular}{|c|c|c|c|c|c|c|c|c|}
\hline \multirow[t]{2}{*}{ Layer } & \multirow[t]{2}{*}{ Soil type } & \multirow[t]{2}{*}{ Depth (m) } & \multicolumn{2}{|c|}{$\begin{array}{l}\text { Poisson's } \\
\text { ratio }\end{array}$} & \multicolumn{2}{|c|}{$\begin{array}{l}\text { Young's } \\
\text { modulus } \\
(\mathrm{MPa})\end{array}$} & \multirow[t]{2}{*}{$\begin{array}{l}\text { Confining pressure correlation } \\
\text { index a }\end{array}$} & \multirow[t]{2}{*}{$\begin{array}{c}\text { Coefficient of shrinkage of } \\
\text { thawed soil (\%) }\end{array}$} \\
\hline & & & $F$ & $T$ & $F$ & $T$ & & \\
\hline 1 & Gravel \& sand & $0 \sim 30$ & 0.30 & 0.35 & 777.0 & 58.0 & 0.499 & 1.81 \\
\hline 2 & Silt & $30 \sim 54$ & 0.35 & 0.40 & 767.0 & 84.0 & 0.2 & 2.09 \\
\hline 3 & Silty sand & $54 \sim 63$ & 0.30 & 0.35 & 777.0 & 58.0 & 0.499 & 1.99 \\
\hline 4 & Clay & $63 \sim 69$ & 0.40 & 0.45 & 737.5 & 62.0 & 0.1 & 3.21 \\
\hline 5 & Sand & $69 \sim 81$ & 0.30 & 0.35 & 777.0 & 58.0 & 0.499 & 1.10 \\
\hline 6 & Clayey silt & $81 \sim 90$ & 0.35 & 0.40 & 767.0 & 84.0 & 0.2 & 3.13 \\
\hline 7 & Silty clay & $90 \sim 96$ & 0.40 & 0.45 & 737.5 & 62.0 & 0.1 & 3.35 \\
\hline 8 & Silt & $96 \sim 102$ & 0.35 & 0.40 & 767.0 & 84.0 & 0.2 & 2.02 \\
\hline 9 & Sand & $102 \sim 135$ & 0.30 & 0.35 & 777.0 & 64.0 & 0.447 & 1.31 \\
\hline 10 & Silt & $135 \sim 147$ & 0.35 & 0.40 & 767.0 & 84.0 & 0.2 & 1.07 \\
\hline 11 & Sand & $147 \sim 153$ & 0.30 & 0.35 & 777.0 & 54.5 & 0.532 & 1.47 \\
\hline 12 & Clay & $153 \sim 156$ & 0.40 & 0.45 & 737.5 & 62.0 & 0.1 & 1.66 \\
\hline 13 & Silty sand & $156 \sim 162$ & 0.3 & 0.35 & 777.0 & 54.5 & 0.532 & 1.24 \\
\hline 14 & Clay & $162 \sim 171$ & 0.4 & 0.45 & 737.5 & 62.3 & 0.1 & 1.75 \\
\hline
\end{tabular}

TABle 3: Physical and mechanical parameters of the casing.

\begin{tabular}{lccccc}
\hline Grade Density $\left(\mathrm{kg} / \mathrm{m}^{3}\right)$ & Young's modulus $(\mathrm{GPa})$ & $\begin{array}{c}\text { Poisson's } \\
\text { ratio }\end{array}$ & $\begin{array}{c}\text { Yield stress (MPa) } \\
\text { Minimum } \\
\text { value }\end{array}$ & $\begin{array}{c}\text { Maximum } \\
\text { value }\end{array}$ & $\begin{array}{c}\text { Strain corresponding to the maximum yield } \\
\text { strength (\%) }\end{array}$ \\
\hline $\mathrm{J} 55$ & 7805 & 210 & 0.3 & 380 & 517 \\
\hline
\end{tabular}

TABLE 4: Parameters of the contact properties.

\begin{tabular}{|c|c|c|c|c|c|c|c|}
\hline \multirow{2}{*}{ Layer } & \multirow{2}{*}{ Soil type } & \multicolumn{2}{|c|}{ Tangential direction } & \multirow{2}{*}{ Cohesive force $(\mathrm{MPa})$} & \multicolumn{3}{|c|}{ Damage } \\
\hline & & Friction coefficient & Elastic sliding & & Initial value & Evolution & Stability coefficient \\
\hline 1 & Gravel and sand & 0.624 & 0.05 & 0.1 & 0.05 & 0.1 & 0.001 \\
\hline 2 & Silt & 0.531 & 0.1 & 0.4 & 0.1 & 0.2 & 0.001 \\
\hline 3 & Silty sand & 0.624 & 0.05 & 0.75 & 0.05 & 0.1 & 0.001 \\
\hline 4 & Clay & 0.268 & 0.1 & 1.0 & 0.1 & 0.2 & 0.001 \\
\hline 5 & Sand & 0.624 & 0.05 & 0.75 & 0.05 & 0.1 & 0.001 \\
\hline 6 & Clayey silt & 0.531 & 0.1 & 0.5 & 0.1 & 0.2 & 0.001 \\
\hline 7 & Silty clay & 0.268 & 0.1 & 0.75 & 0.1 & 0.2 & 0.001 \\
\hline 8 & Silt & 0.531 & 0.1 & 0.4 & 0.1 & 0.2 & 0.001 \\
\hline 9 & Sand & 0.624 & 0.05 & 0.75 & 0.05 & 0.1 & 0.001 \\
\hline 10 & Silt & 0.531 & 0.1 & 0.4 & 0.1 & 0.2 & 0.001 \\
\hline 11 & Sand & 0.624 & 0.05 & 0.6 & 0.05 & 0.1 & 0.001 \\
\hline 12 & Clay & 0.268 & 0.1 & 1.0 & 0.1 & 0.2 & 0.001 \\
\hline 13 & Silty sand & 0.624 & 0.05 & 0.75 & 0.05 & 0.1 & 0.001 \\
\hline 14 & Clay & 0.268 & 0.1 & 1.0 & 0.1 & 0.2 & 0.001 \\
\hline
\end{tabular}

the deformation value is related to the material properties of permafrost and thawed soil, as well as the degree of restraint the permafrost and casing demonstrates to the thawed soil. As a result of various material properties of the casing and thawed soil, negative friction on the outer wall of the casing will gradually appear and increase with the increase of thawed soil deformation. Casing settlement deformation will occur under the combined action of dead weight and negative friction. As the rigidity of casing material is greater than that of thawed soil, the settlement deformation of the casing is always less than that of thawed soil.
With the gradual expansion of the thaw bulb, constraints exerted on thawed soil by the permafrost and casing gradually weaken, while the settlement deformation of thawed soil gradually increases. When casing stress is in an elastic stage, the settlement and deformation difference value between the top of the casing and the base of the thawed soil and the negative friction acting on the casing increase gradually. These increases cause an increase in casing settlement and deformation. After the casing stress enters the plastic stage, approximate synchronous settlement and deformation occur between the thawed soil and the casing. At 


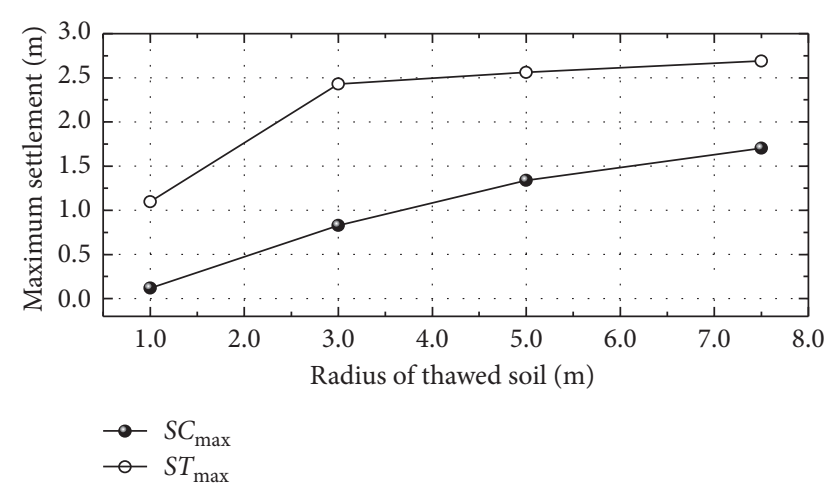

Figure 3: Curve of maximum settlement deformation with the expansion of the thaw bulb radius.

this time, the friction force on the lateral wall of casing in the plastic stage does not change much when compared with casing in the ultimate elastic state. The maximum settlement deformation difference between the thawed soil and the casing remains basically unchanged.

After the casing of heavy oil wells has been in operation for more than 20 years, the thaw bulb radius is about $7.5 \mathrm{~m}$ and remains basically unchanged. At this time, the casing will become stable under the influence of the thawed soil. Therefore, it is necessary to monitor the health state of heavy oil well casing operation during the first 20 years.

3.2. Analysis of Vertical Displacement. To study interactions between thawed soil and casing, casing wall and the soil adjacent to the outer wall of the casing were examined; the vertical displacement $D_{V}$ is distributed along the depth direction as shown in Figure 4.

The following conclusions can be drawn from Figure 4:

(1) The variation in vertical displacement of the thawed soil and the casing with depth are greatly affected by the size of the thaw bulb.

The vertical displacement distribution of the thawed soil is obviously nonlinear with depth, while that of the casing is approximately linear with depth when the thaw bulb radius $R_{\mathrm{TB}}$ reaches $1.0 \mathrm{~m}$. The vertical displacement of the thawed soil is approximately linearly distributed with depth. That of the casing has an obvious inflection point with depth when $R_{\mathrm{TB}} \geq 3.0 \mathrm{~m}$.

(2) With the gradual expansion of the thaw bulb, the curve inflection point of the casing's vertical displacement with depth gradually approaches the ground surface. On both sides of the inflection point, the casing's vertical displacement with depth is approximately linear.

It can be seen from the analysis that the location of the deformation inflection point on the casing is the location where the stress yield occurs under the effect of negative friction. On the side where the casing strength has not reached the yield state, the settlement deformation of casing in the elastic stage gradually accumulates, while the casing's vertical displacement with depth is approximately linear. On the other side of the casing, where the strength has reached its yield state, the settlement deformation reflects the settlement deformation of the thawed soil. Therefore, the vertical displacement curve for casing with depth is similar to that of the external thawed soil, but there is a certain difference near the point where the casing strength begins to yield. Besides, due to the gradual expansion of the thaw bulb, the negative friction acting on the casing increases, which eventually leads the casing's stress yield inflection point to gradually approach the ground surface. This phenomenon is discussed in detail in the subsequent analysis of casing stress. For the casing's vertical displacement curve with depth, the depth of the deformation inflection point also becomes shallower with the expansion of the thaw bulb.

(3) When the thaw bulb radius is small, the thawed soil's vertical displacement fluctuates rapidly near the boundaries of some of the soil layers.

After the thawing of permafrost, the volume of thawed soil will be smaller than that of the permafrost due to ice disappearance and thawed soil consolidation. Without lateral restraint, the gradual accumulation of settlement deformation in the thawed soil leads to the largest settlement deformation at the top of the thaw bulb surface. In theory, the thawed soil is bound to be constrained by the frozen soil and the casing, creating a tension stress state in some parts of the thawed soil. Existing survey data [22] have confirmed that when the tensile stress in the thawed soil exceeds its tensile limit state, an internal cavity will form in the thawed soil, and its vertical displacement will create an abrupt change on both sides of the cavity. There is no cavity in the thawed soil because the fracture failure behaviors of the soil are not considered in the model calculation. However, when the thaw bulb radius is small $\left(R_{\mathrm{TB}}=1.0 \mathrm{~m}\right)$, there are strong constraints on the settlement process of the thawed soil between the permafrost and thawed soil and between the casing and the thawed soil. The curve of the vertical displacement of thawed soil with depth changes abruptly near the boundary of some soil layers. It can be seen that there is a large thaw bulb with a tensile stress state in the subsequent analysis of thawed soil stress. While the thaw bulb radius is large $\left(R_{\mathrm{TB}} \geq 3.0 \mathrm{~m}\right)$, the thawed soil is less restrained by permafrost and casing during settlement. Settlement deformation accumulates gradually; hence, the curve of the vertical displacement with depth demonstrates an approximately linear distribution.

3.3. Analysis of Thawed Soil Stress. Stress redistribution in the thaw bulb is crucial for understanding the mechanical behaviour of casing during ground subsidence. Figure 5 shows the vertical and horizontal stresses of the soil layer near the casing as the thaw bulb expands.

The following can be seen from Figure 5: 


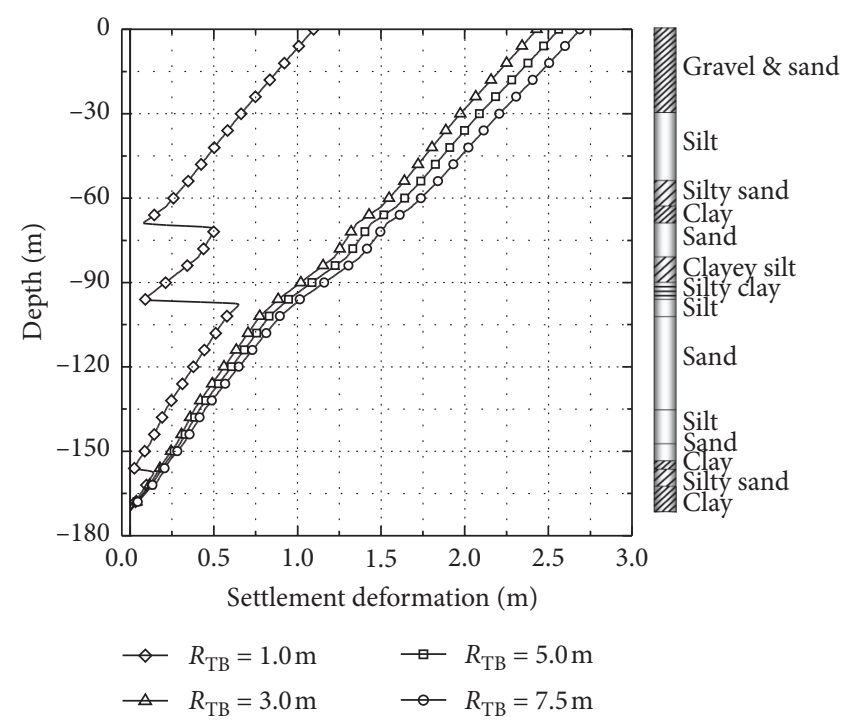

(a)

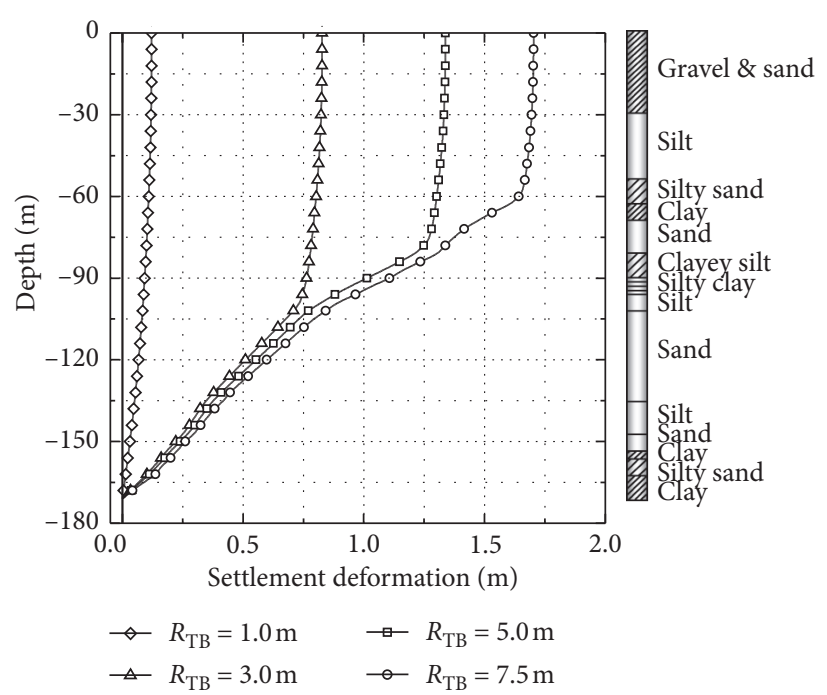

(b)

FIGURE 4: Vertical displacement distribution of the thawed soil and the casing with depth: (a) vertical displacement of thawed soil and (b) vertical displacement of casing.

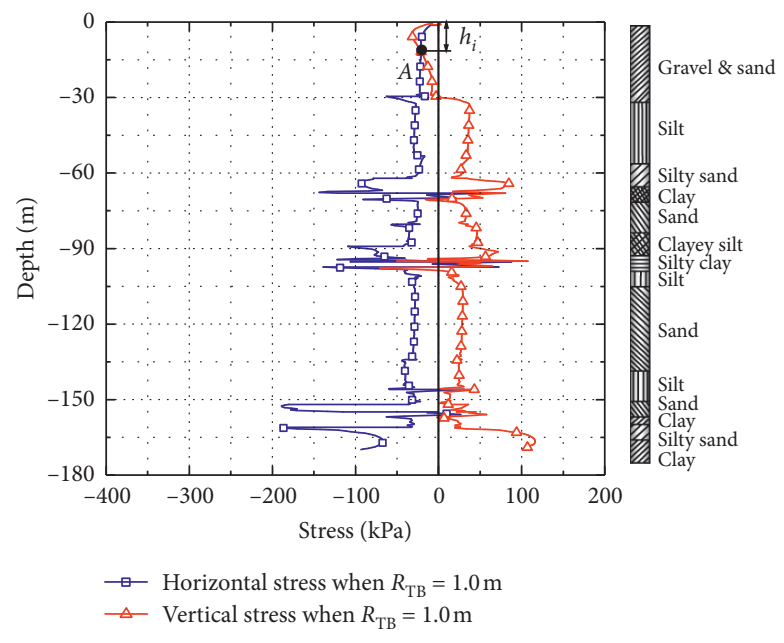

(a)

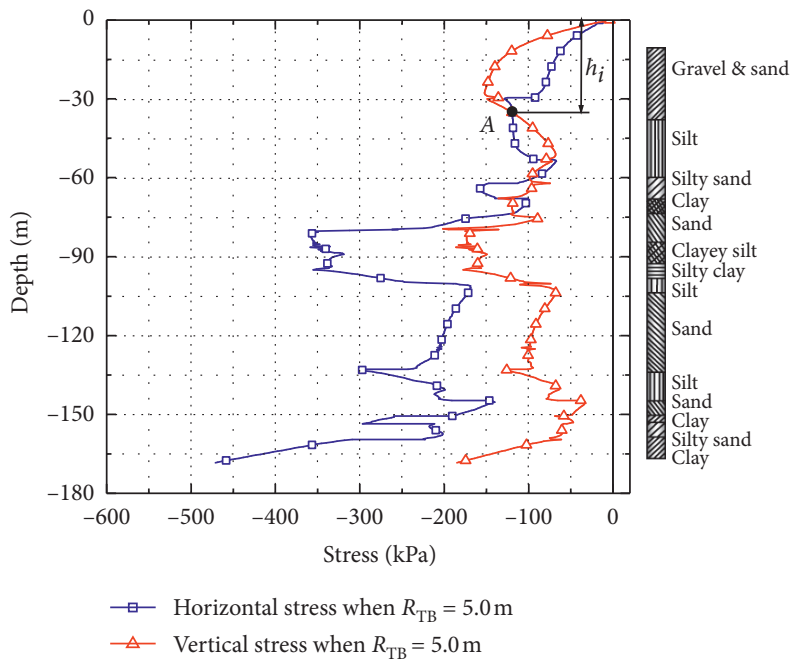

(c)

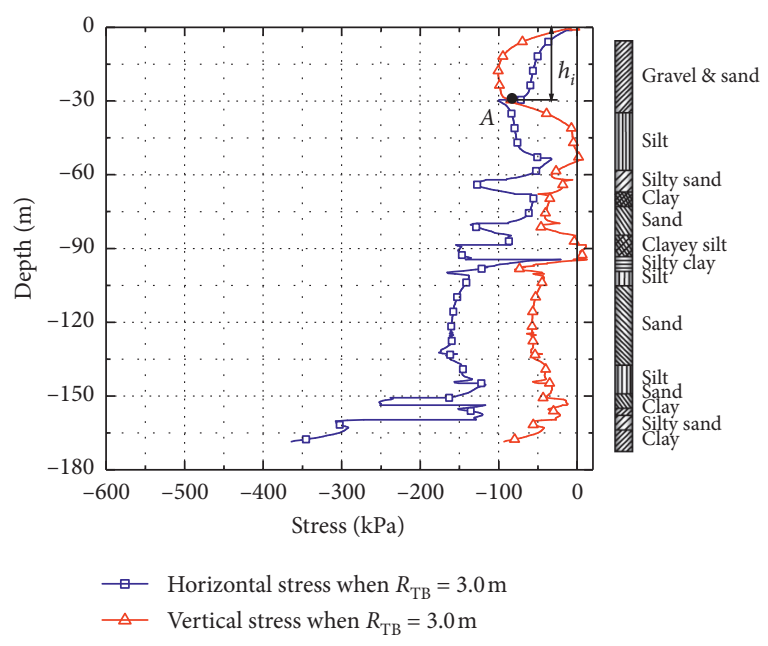

(b)

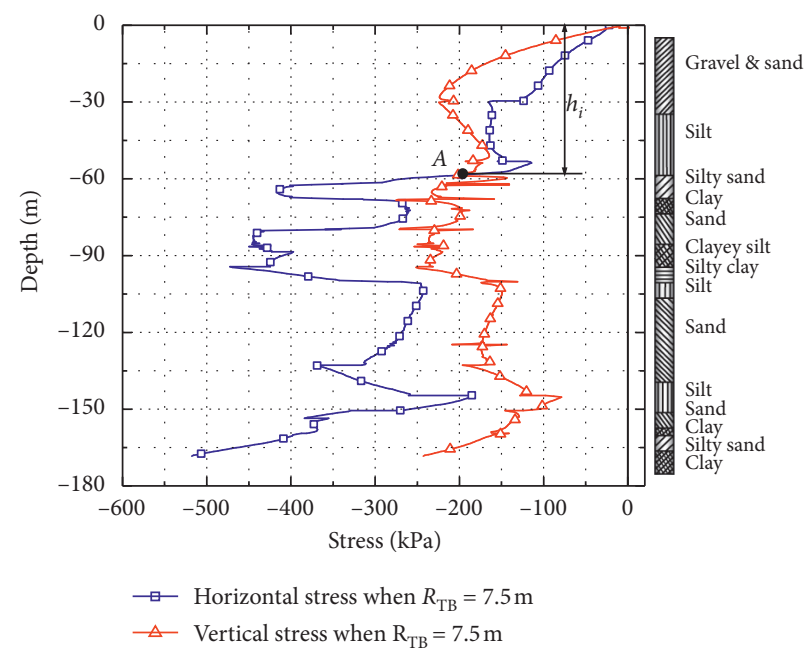

(d)

Figure 5: Continued. 


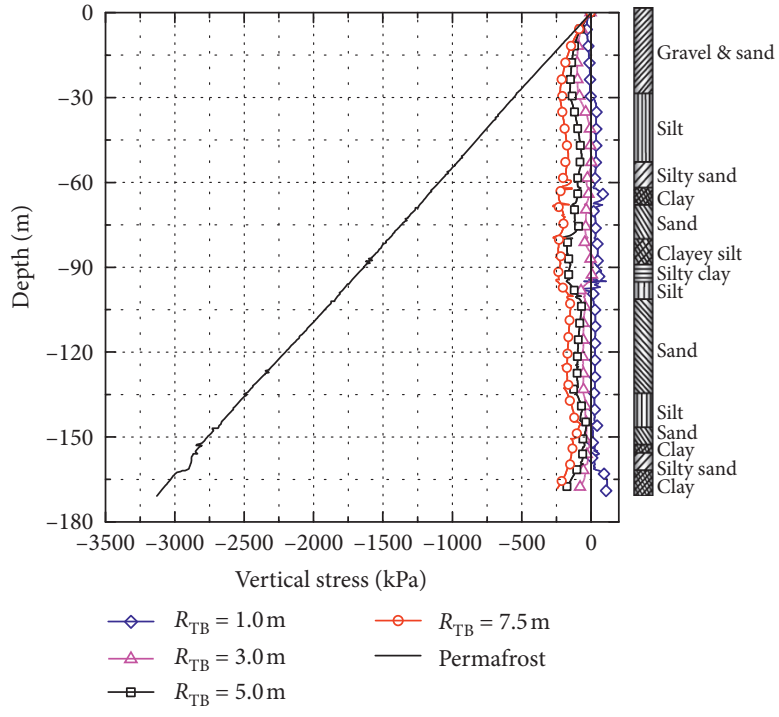

(e)

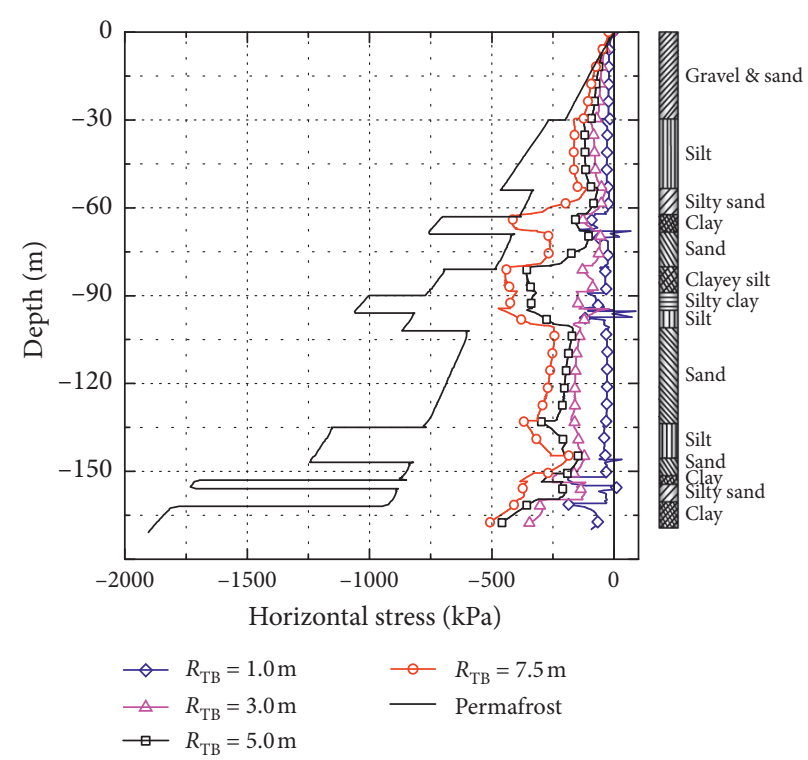

(f)

Figure 5: Distribution curve for thawed soil stress with depth: (a) $R_{\mathrm{TB}}=1.0 \mathrm{~m}$, (b) $R_{\mathrm{TB}}=3.0 \mathrm{~m}$, (c) $R_{\mathrm{TB}}=5.0 \mathrm{~m},(\mathrm{~d}) R_{\mathrm{TB}}=7.5 \mathrm{~m},(\mathrm{e})$ vertical stress on the thawed soil, and (f) horizontal stress of the thawed soil.

(1) The vertical stress at the permafrost boundary increases linearly with an increase in soil depth, and the horizontal stress changes abruptly at the soil layer boundary. This latter change is due to the influence of Poisson's ratio. Figures 5(e) and 5(f) can clearly observe the above phenomenon.

(2) The sensitivity of the thawed soil vertical stress to depth is higher than that of its horizontal stress.

The melting of ice lenses and pore ice in the permafrost causes soil volume shrinkage, ground settlement deformation, a decrease in Young's modulus of thawed soil, and the development of friction force on the casing's lateral walls. According to classical soil mechanics, the horizontal stress value of the soil should be less than its vertical stress value. However, in Figures 5(a)-5(d), it can be clearly observed that when the depth of thawed soil exceeds a certain value, the vertical stress value of the thawed soil is less than its horizontal stress value. In addition, it can be seen from Figure 5(d) that when the thaw bulb radius reaches $7.5 \mathrm{~m}$, the vertical stress of the thawed soil at $171.0 \mathrm{~m}$ decreases from about $3.0 \mathrm{MPa}$ to about $0.25 \mathrm{MPa}$, and the horizontal stress decreases from about 2.0 MPa to about $0.5 \mathrm{MPa}$. Obviously, the vertical stress of thawed soil is more sensitive to the changing of soil depth than horizontal stress.

(3) The vertical stress on the thawed soil gradually transits from a tensile stress state to a compressive stress state with the expansion of the thaw bulb radius, and the value of vertical stress increases continuously, while the horizontal stress of the thawed soil is always in the compressive stress state. Soil depth $h_{i}$, where the horizontal stress value is at first greater than the vertical stress value, gradually deepens as the thaw bulb radius expands.

It can be seen from Figure 5(a) that the horizontal stress on the thawed soil is compressive stress when the thaw bulb radius reaches $1.0 \mathrm{~m}$, while the vertical stress is more tensile. The vertical stress and horizontal stress of the soil layer in the thaw bulb are both compressive when the thaw bulb radius is greater than $1.0 \mathrm{~m}$. Moreover, at point A, the vertical stress value of the thawed soil is greater than that of horizontal stress when its depth is less than $h_{i}$ away from the ground surface. Conversely, the value horizontal stress on the thawed soil is greater than the vertical stress when depth is greater than $h_{i}$.

The vertical stress at the permafrost boundary is greater than the horizontal stress, and compressive stress prevails in both directions, in conformation with classical soil mechanics theory. However, in the thaw bulb, the vertical stress value on the thawed soil is greater than the horizontal stress value only in the formation depth $h_{i}$ near the ground surface, while the vertical stress value of thawed soil is less than the horizontal stress value beyond the formation depth $h_{i}$. When the thaw bulb radius is smaller, the soil layer's vertical stress exhibits a tensile state over a large range. These stress phenomena in the thaw bulb are mainly a result of the fact that the finite element model did not account for the fracture failure criteria in the soil's constitutive properties and stress redistribution in the thaw bulb. The depth $h_{i}$ is related to the physical properties of permafrost and thawed soil, the size of the thaw bulb, and the vertical deformation of the casing. As $h_{i}$ gradually increases with the increase of $R_{\mathrm{TB}}$, the internal laws of these interactions are a necessary object of future study.

3.4. Analysis of the Vertical Stress and Negative Friction on Casing. The change law for the casing's vertical stress with the expansion of the thaw bulb is shown in Figure 6(a). The 


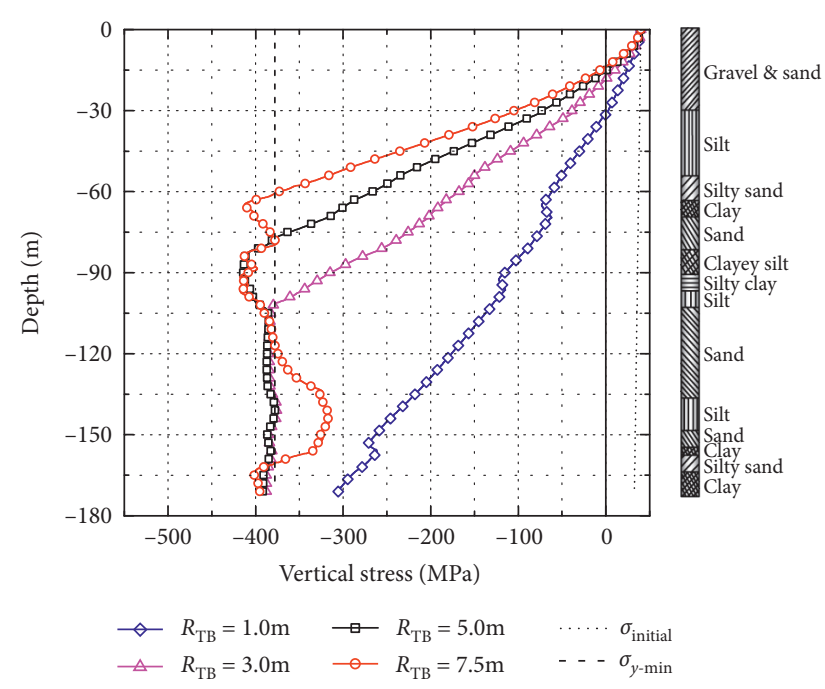

(a)

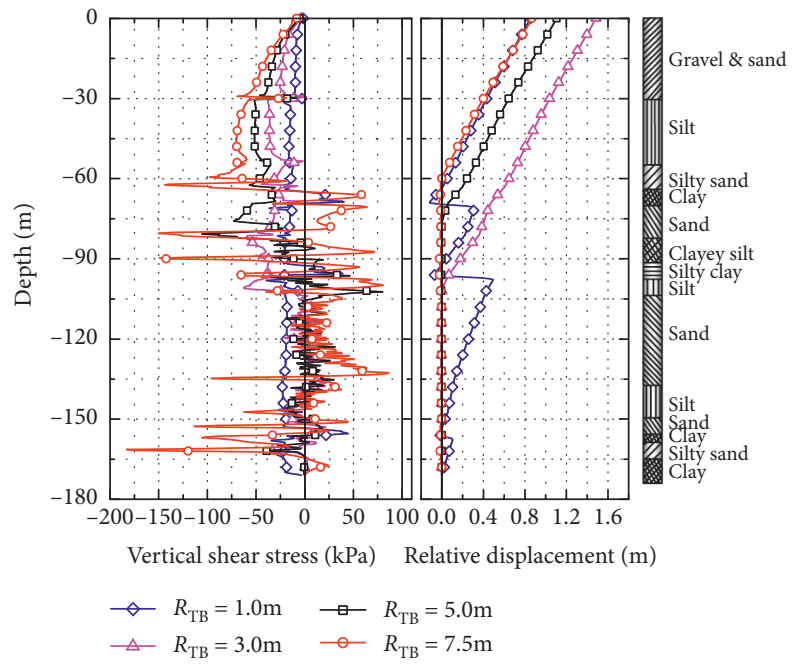

(b)

Figure 6: Distribution curve for casing vertical stress and its shear stress with depth: (a) vertical stress and (b) vertical shear stress and relative displacement.

curve of the J55 API casing's minimum plastic yield stress $\sigma_{y-\min }$ and the change curve of the casing's initial construction tensile stress $\sigma_{\text {initial }}$ with depth are shown in Figure 6(a). In order to facilitate analysis, the curves for the vertical shear stress on the casing's lateral wall with depth and the relative displacement of the casing and soil layer with depth are plotted in Figure 6(b).

The graphs illustrate the following:

(1) Due to the existence of the casing initial stress $\sigma_{\text {initial }}$, the casing's vertical stress presents a tensile stress state within a certain depth range from the ground. As the depth gradually increases, the casing's vertical stress gradually changes to a compressive stress state.

(2) When $R_{\mathrm{TB}}=1.0 \mathrm{~m}$, due to the continuous negative friction and deadweight acting on the lateral casing wall, the casing's vertical stress increases almost linearly with depth.

(3) When $R_{\mathrm{TB}}>1.0 \mathrm{~m}$, the casing's vertical stress exceeds the minimum plastic yield stress. As it begins to yield, the location of the casing's initial stress yield gradually becomes shallower with the expansion of the thaw bulb. Before the casing has yielded, there is obvious negative friction on the lateral casing wall, but after the casing has yielded, there is no significant negative friction.

It can be seen from Figure 6(a) that when $R_{\mathrm{TB}}=3.0 \mathrm{~m}$, the depth of the casing strength yield is about $100 \mathrm{~m}$, while when $R_{\mathrm{TB}}=5.0 \mathrm{~m}$ and $7.5 \mathrm{~m}$, it is about $75 \mathrm{~m}$ and $60 \mathrm{~m}$, respectively. The distribution law for casing strength yielding depth with $R_{\mathrm{TB}}$ is similar to the law for the inflection point of casing vertical displacement changes with $R_{\mathrm{TB}}$. As can be seen from Figure 6(b), the gravity stress on the casing is the same at the same depth. The negative friction on the lateral casing wall increases with the expansion of the thaw bulb, as does the vertical stress on the casing. When the vertical stress reaches or exceeds its yield stress, the casing begins to yield. As vertical stress of casing with a large thaw bulb reaches the yield state, the depth where the casing yields gradually becomes shallower with the expansion of the thaw bulb. Due to the interaction between the casing and the surrounding soil, the vertical stress on the casing fluctuates slightly adjacent to its yield stress $\sigma_{y \text {-min }}$.

\section{Limitations of the Model}

Due to the lack of physical and mechanical parameters after the formation depth exceeds $171 \mathrm{~m}$ and the fact that the casing failure depth is mainly within $150 \mathrm{~m}$, the simulation analysis model only considered the casing stress state within a depth of $171 \mathrm{~m}$. Based on the technology employed in constructing heavy oil wells, a certain thickness was presumed for the cement grouting layer on the lateral casing wall. After the grouting layer is solidified, the casing's buckling resistance improves and its risk of settlement deformation is reduced. Because the thickness of the cement grouting layer and the parameters of its contact interface with the surrounding permafrost are difficult to determine, the cement grouting layer was ignored in the model calculation process. However, the mechanical behaviour of the interface between the frozen soil and the concrete will also have a certain impact on the force and deformation of the structure [29]. Thus, it should be noted that ignoring the cement grouting layer will not produce calculation results which exactly reflect the real state.

The actual production process of heavy oil includes injection well casing and production well casing. These two casings do not have identical temperature fields and stress states. In order to facilitate production management, in general, multiple heavy oil production well casings are concentrated in one place at a horizontal distance of about $5.5 \mathrm{~m}$. The influence of the interaction between casings on 
the thawing settlement of permafrost and the healthy operation of the casings is complicated. This paper has examined simple working conditions and only considers single production well casing, but it still provides a reference for future analyses of the interactions between multiple adjacent well casings.

To analyze the major factors influencing the healthy operating status of the casing, the model made three assumptions which resulted in inflated calculation results for casing stress and deformation. Use of these calculation results must therefore remain conservative.

Given the above-mentioned shortcomings of the analysis model, the analysis model will continue to be improved, hoping that the research results can provide more reference for actual production.

\section{Conclusion}

Based on the simulation calculation of a single oil casing in a producing well in a permafrost region, the deformation and stress distribution of casing and thawed soil with the different thaw bulb in permafrost have been analyzed. The internal mechanisms of vertical settlement displacement development and stress redistribution for thawed soil and casing were also discussed. The following conclusions can be drawn:

(1) The maximum settlement of thawed soil and casing was positively related to the gradual expansion of the thaw bulb. The settlement of thawed soil was larger than that of the casing. Though the maximum settlement difference between thawed soil and casing increased first, it then decreased and finally tended to be constant due to stabilization of the thaw bulb's expansion, meaning that actual oil well project tends to stabilize over time.

(2) When the thaw bulb was small, the vertical displacement curve for the thawed soil with depth fluctuated acutely due to stress redistribution. The law for vertical displacement of the casing with depth demonstrated a positive correlation and linear distribution. As the thaw bulb gradually expands, the vertical displacement of the thawed soil increases linearly with depth. The inflection point appears in the vertical displacement curve of the casing with depth, and the location of the inflection point gradually approaches the ground surface with the expansion of the thaw bulb. In addition, the casing's vertical displacement with depth on both sides of the inflection point changed approximately linearly, but the stress state of the casing was completely different.

(3) The vertical stress on the thawed soil gradually transitioned from tensile stress to compressive stress with the expanding of the thaw bulb, while the horizontal stress was always in the compressive state. The depth $h_{i}$ of the soil layer where the horizontal stress value was greater than the vertical stress value for the first time gradually deepened with the increase of the thaw bulb radius. In addition, the thawed soil's vertical stress with soil depth was more sensitive to change than was its horizontal stress.

(4) When the vertical stress of the casing exceeded the minimum plastic yield stress, the casing began to yield. The location where the casing stress began to reach the yield state gradually became shallower with the expansion of the thaw bulb. In addition, though there was no significant negative friction on the lateral of casing wall when the casing strength reached yield, there was obvious negative friction on the lateral of casing wall when the casing strength was in an elastic stress state. Due to the existence of continuous negative friction and deadweight, the vertical value stress on the casing increased gradually as the casing location deepened.

In short, the thaw bulb around the casing of a single heavy oil-producing oil well in an Arctic permafrost region examined in this study basically no longer expanded after 20 years of operation due to heat balance. As such, the casing will become stable under the influence of thawed soil. These analysis results can be used to predict the final healthy operating status of oil well casings, provide theoretical references for the design of new oil wells, and provide technical support for the treatment of casing subsidence in existing oil wells.

\section{Data Availability}

The data used to support the findings of this study are included within the article.

\section{Conflicts of Interest}

The authors declare no conflicts of interest.

\section{Acknowledgments}

This scientific research program was supported by the National Natural Science Foundation of China (no. 42001059) and the Natural Science Foundation of Hebei Province, China (E2020210044).

\section{References}

[1] L. J. Yang, X. M. Wang, and Z. D. Cui, "Current and comprehensive regulation measures of casing damage in Jidong oilfield," Oil Drilling \& Production Technology, vol. 25, no. 2, pp. 79-82+92, 2003.

[2] L. Yu and M. Bo, "New technology for casing damage prevention and cure of thermal production wells in Liaohe oilfield," Petroleum Exploration and Development, vol. 32, no. 1, pp. 116-118, 2005.

[3] P. Q. Li, "Analysis of causes responsible for damages of casings occurring during oil/gas field exploration stage-"standard study, failure analysis and typical cases of oil tubing/casing" (2)," Steel Pipe, vol. 35, no. 5, pp. 53-60, 2006.

[4] A. I. Mohammed, B. Oyeneyin, B. Atchison et al., "Casing structural integrity and failure modes in a range of well types-a review," Journal of Natural Gas Science and Engineering, vol. 68, 2019. 
[5] T. Wang, S. 1. Yang, W. H. Zhu et al., "Law and countermeasures for the casing damage of oil production wells and water injection wells in Tarim oilfield," Petroleum Exploration and Development Online, vol. 38, no. 3, pp. 352-161, 2011.

[6] C. M. Matthews, T. Dessein, and S. Yuen, "Comprehensive thaw subsidence assessments for Kuparuk DS-2A," in Draft Final Report to ConocoPhillips Alaska Inc C-FER Technologies, Edmonton, Canada, 2015.

[7] G. Xu, P. Liu, Q. L. Zhang et al., "Analysis of casing damage on typical wells in bohai oilfield," Surface Technology, vol. 46, no. 7, pp. 168-172, 2017.

[8] J. H. Jia, "Casing failure mechanism of thermal production wells and casing strength optimization design," Journal of Safety Science and Technology, vol. 7, no. 9, pp. 121-125, 2011.

[9] F. Yin and D. Gao, "Mechanical analysis and design of casing in directional well under in-situ stresses," Journal of Natural Gas Science And Engineering, vol. 20, pp. 285-291, 2014.

[10] Q. J. Zhu and J. Chen, "Deformation analysis and fracture mechanism of steel casing in oil wells," Applied Mechanics and Materials, vol. 467, pp. 317-322, 2013.

[11] J. J. Wang, L. H. Han, X. Z. Yan et al., "Analysis of the casing string prestressed relaxation effect in heavy oil steam injection well," China Petroleum Machinery, vol. 41, no. 8, pp. 65-67, 2013.

[12] R. J. Xie, S. J. Liu, Y. Wu et al., "Study on the casing string mechanics and feasibility of pre-stressed cementing in offshore thermal recovery wells," China Offshore Oil and Gas, vol. 27, no. 3, pp. 113-118+125, 2015.

[13] L. J. Lu, S. B. Feng, and B. Zhang, "Method for designing casing stem strength in heavy-oil steam injection wells," Journal of Oil and Gas Technology, vol. 31, no. 2, pp. $364-366+18,2009$.

[14] R. Mitchell (Halliburton), "Casing design with flowing fluids," SPE Drilling \& Completion, vol. 26, no. 3, pp. 432-435, 2011.

[15] J. Wu (Chevron ETC), "Improve casing design for WCD in deepwater wells," in Proceedings of the SPE Annual Technical Conference and Exhibition, New Orleans, LA, USA, September 2013.

[16] C. Y. Hu, C. Ai, F. Y. Tao, F. Wang, and M. Yan, "Optimization of well completion method and casing design parameters to delay casing impairment caused by formation slippage," in Proceedings of the SPE/IADC Middle East Drilling Technology Conference and Exhibition, Abu Dhabi, UAE, January 2016.

[17] L. D. Yu, "Distribution of world heavy oil reserves and its recovery technologies and future," Special Oil \& Gas Reservoirs, vol. 8, no. 2, pp. 98-103+110, 2001.

[18] S. J. Jiang, X. D. Tang, Y. Y. Zhang et al., "Adaptability of airinjection low-temperature catalytic oxidation technology in heavy oil production," Special Oil \& Gas Reservoirs, vol. 21, no. 5, pp. 130-133+157-158, 2014

[19] Z. H. Zhu, M. Du, and H. Y. Han, "New technique of shallowlayer super-viscous oil production in Karamay oilfield," Journal of Oil and Gas Technology, no. 3, pp. 441-443 +521, 2007.

[20] A. Shafiei and M. B. Dusseault, "Geomechanics of thermal viscous oil production in sandstones," Journal of Petroleum Science and Engineering, vol. 103, pp. 121-139, 2013.

[21] W. Guan, X. Zhang, C. Xi et al., "Displacement and development characteristics of fire flooding of vertical wells in old heavy oil areas," Petroleum Research, vol. 3, no. 2, pp. 165-179, 2018.
[22] API (American Petroleum Institute), Specification for Casing and Tubing: API Specification 5CT/ISO 11960, American Petroleum Institute, Washington, DC, USA, 8th edition, 2005.

[23] N. Morita and S. Shiozawa, "Stability analysis of casings during plastic deformation," in Proceedings of the SPE Deepwater Drilling and Completion Conference, pp. 129-142, Galveston, TX, USA, September 2014.

[24] F. Zhang, Z. Yang, B. Still et al., "Elastic properties of saline permafrost during thawing by bender elements and bending disks," Cold Regions Science and Technology, vol. 146, pp. 60-71, 2018.

[25] Z. H. Yang, T. C. Sun, J. H. Wang et al., "Well casing subsidence in thawing permafrost: a case study," Journal of Cold Regions Engineering, vol. 34, no. 2, 2020.

[26] N. Janbu, "Soil compressibility as determined by oedometer and triaxial tests," in Proceedings of European Conference on Soil Mechanics and Foundation Engineering (ECSMFE), pp. 19-25, Wiesbaden, Germany, 1963.

[27] ABAQUS, ABAQUS Analysis User's Guide, Dassault Systèmes, Providence, RI, USA, 2016.

[28] EBA, "Kuparuk deep core permafrost project: core descriptions," EBA File: E14103016. Electronic File Issued by EBA, A Tetra Tech Company, Technical Report to CPAI, EBA, Paris, France, 2013.

[29] T. C. Sun, X. J. Gao, Z. R. Yue et al., "Experimental study on the adfreezing strength of the interface between silt and concrete," Chinese Journal of Rock Mechanics and Engineering, vol. 39, no. 5, pp. 1032-1039, 2020. 